\title{
Avaliação clínica e enzimática de cães com hepatite tóxica aguda tratados pela silimarina
}

\author{
Clinical and enzymatic evaluation in dogs with acute toxic hepatitis \\ treated by silymarin
}

\author{
Deila Rosély Schossler, ${ }^{\star}$ João Eduardo Schossler** e Cândido Fontoura da Silva ${ }^{\star \star \star}$
}

\begin{abstract}
Resumo
Neste experimento foi utilizado o tetracloreto de carbono como agente experimental de produção de hepatite tóxica aguda e posterior tratamento pela silimarina. Foram utilizados três grupos de cinco cães, sendo todos intoxicados pelo tetracloreto de carbono na dose de $0,5 \mathrm{ml} / \mathrm{kg}$, dos quais, os grupos II e III foram tratados pela silimarina, na dose de $4 \mathrm{mg} /$ $\mathrm{kg} / 24 \mathrm{hs}$ e $8 \mathrm{mg} / \mathrm{kg} / 24 \mathrm{hs}$, respectivamente, durante 15 dias. Observou-se o estado clínico e sensibilidade hepática dos animais, bem como foram mensuradas a ALT e FA, 24 horas antes do início do experimento e posteriormente em intervalos de 48 horas, durante 15 dias. Todos os animais apresentaram inapetência inicial e diarréia com estrias de sangue, normalizando-se após 24 horas. A sensibilidade hepática foi de menor intensidade nos grupos II e III. A ALT e FA mostraram-se aumentadas em todos os animais, atingindo 307,5 e 8,5 vezes, respectivamente, os valores normais, sendo que a ALT apresentou-se menor nos animais tratados. Diante disto, conclui-se que a silimarina é capaz de diminuir os níveis de ALT, em animais intoxicados pelo tetracloreto de carbono, indicando um efeito regenerador hepático, não havendo diferença significativa entre as doses empregadas nos animais tratados.
\end{abstract}

Palavras-chave: fígado; silimarina; cães.

\section{Introdução}

As hepetopatias constituem-se numa alteração clínica de relativa freqüência na casuística médico-veterinária, sendo que as opções terapêuticas disponiveis comercialmente restringem-se, em sua maioria, à utilização de uma combinação de complexos vitamínicos e estimulantes do metabolismo hepático, aos quais é atribuído um efeito hepatoprotetor e hepatoestimulante, esperando-se proporcionar meios para a recuperação normal do tecido hepáticolesado.

O emprego da silimarina tem sido estudado por vários autores (Bulles et al., 1975, Bindoli et al., 1977, Candel et al., 1978, Magliulo et al., 1979, Lorenz et al, 1984, Valenzuela \& Guerra , 1985, Yao-Cheng, 1991, Conti et al, 1992, Muriel et al., 1992, Haková \& Misurová, 1993, Wu et al., 1993) devido à sua ação hepatoprotetora.

A silimarina, uma 3-oxiflavona, tem como seu componente principal a silibina, e como componentes secundários os isômeros desta, que são a silidianida e a silicristina (Bulles et al.,1975, Lorenz et al., 1984, Arcari et al., 1992, Muriel et al., 1992). Trata-se de uma substância ativa, originada do caldo mariano (Silybum marianum), tendo sido comprovado como um agente anti-hepatotóxico efetivo contra os efeitos tóxicos de várias substâncias, incluindo o tetracloreto de carbono, porém seu mecanismo protetor ainda não foi totalmente elucidado, mas a teoria mais aceita é que a silimarina provoca uma ação estabilizadora de membrana, prevenindo ou inibindo a peroxidação lipídica (Bindoli et al., 1977, Magliulo et al., 1979, Valenzuela \& Guerra, 1985, Yao-Cheng, 1991, La Lastra et al., 1992, Muriel et al., 1992).

A silimarina é um fármaco de comercialização recente para uso humano que, segundo informações do fabricante, proporciona um efeito estimulante específico sobre os hepatócitos, com aceleração do processo regenerativo celular e por conseqüência na recuperação das hepatopatias.

De acordo com Haroká \& Misurová (1993), a silimarina é capaz de proteger as células hepáticas diretamente pela estabilização de estruturas da membrana, por diminuição da permeabilidade e alteração no conteúdo lipídico desta. A silimarina também pode influenciar no metabolismo intracelular incluindo a síntese de RNA.

O tetracloreto de carbono $\left(\mathrm{CCl}_{4}\right)$ é um hidrocarboneto clorado, quimicamente afim do clorofórmio. Foi preparado pela primeira vez em 1849, e foi utilizado por Simpson,

\footnotetext{
"Méd. Vet., Mestre, Prof. Assistente Depto. Morfologia, Centro de Ciências da Saúde, Universidade Federal de Santa Maria, 97105-900, Santa Maria, RS. Autor para correspondência.

"Méd. Vet., Doutor, Prof. Adjunto Depto. Clínica Pequenos Animais, CCR, UFSM.

"."Méd. Vet., Mestre, Prof. Titular Depto. Clínica Pequenos Animais, CCR, UFSM.
} 
o descobridor da anestesia clorofórmica, mas logo foi abandonado devido à sua alta toxicidade (Goodman \& Gilman, 1991). Este composto foi a primeira droga realmente eficaz no tratamento das fascioloses, sendo seu uso como anti-helmíntico substituído por outras drogas menos tóxicas (Frimmer, 1982, Meyer Jones et al., 1983).

Atualmente o tetracloreto de carbono é usado como reagente e solvente na indústria química. Também é utilizado como droga capaz de provocar hepatite tóxica em animais de experimentação (Gallagher, 1961, Pérez,1964). O tetracloreto de carbono é um agente bloqueador da secreção de triglicerídeos do fígado para o sangue, resultando num acúmulo de gordura nos hepatócitos (Pérez, 1964, Frimmer, 1982), produzindo uma hepatite tóxica aguda.

Objetivando-se avaliara ação da silimarina sobre os níveis séricos de alanina aminotransferase (ALT) e fosfatase alcalina (FA), foram utilizados três grupos de cinco animais intoxicados pelo tetracloreto de carbono, sendo então dois grupos submetidos ao tratamento com diferentes dosagens de silimarina.

\section{Material e método}

A experimentação foi desenvolvida utilizando-se o cão ( $C a$ nis familiaris), contando com 15 animais de idade e peso variáveis, sendo oito fêmeas e sete machos, sem raça definida, clinicamente sadios, provenientes do Biotério Central da Universidade Federal de Santa Maria.

Os cães foram alojados em box individuais, em condições de luminosidade e temperatura naturalmente mantidas, $e$ receberam ração balanceada padronizada diariamente eágua ad libitum. Os animais foram submetidos a um período de adaptação de uma semana anterior ao início do experimento.

Todos os animais receberam $0,5 \mathrm{ml} / \mathrm{kg}$ de tetracloreto de carbono adicionado de igual porção de óleo vegetal ${ }^{\mathrm{b}}$, administrado através de sonda gástrica, com o animal sob anestesia geral realizada com tiopental sódicoc ${ }^{\circ}$, na dose de $25 \mathrm{mg} / \mathrm{kg}$, por via intravenosa. Foram dispostos aleatoriamente em três grupos de cinco animais cada, numerados de 1 a 5 , da seguinte maneira:

- Grupo I: somente intoxicados.

- Grupo Il: intoxicados e tratados com $4 \mathrm{mg} / \mathrm{kg}$ de silimarina ${ }^{d}$. - Grupo III: intoxicados e tratados com $8 \mathrm{mg} / \mathrm{kg}$ de silimarina.

A silimarina foi administrada oito horas após estabelecida a intoxicação, em suspensão líquida, por via oral, em intervalos de 24 horas durante 15 dias. As enzimas hepáticas ALT e FA, foram mensuradas previamente à intoxicação, bem como 24 horas após e sequencialmente em intervalos de 48 horas até o final do período experimental no décimo quinto dia.
O sanguve dos animais foi colhido através de venipunção cefálica, utilizando-se seringas de vidro de $5 \mathrm{ml}$ esterilizadas e agulhas descartáveis de calibre $25 \times 8$, tendo sido acondicionado em tubos de ensaio sem anticoagulante.

A centrifugação foi realizada durante 15 minutos a 1.500 rotações por minuto, imediatamente após a colheita. Após obtenção do soro, no qual foram feitas as dosagens de ALT e FA no mesmo dia da colheita, empregando-se kits enzimáticos Biocline de alanina aminotransferase e fosfatase alcalina, com determinação das absorbâncias através de espectrofotometria.

Durante o período do experimento foi observado o estado clínico em cada animal: micção, defecação, coloração das mucosas e a sensibilidade hepática; para esta avaliação foi usado o seguinte protocolo:

$$
\begin{aligned}
& \text { - : sem reação } \\
& \text { +: reação ao toque profundo } \\
& \text { ++: reação ao toque superficial } \\
& \text { +++: reação ao toque superficial, com vocalização }
\end{aligned}
$$

Os valores de ALT e FA, de cada grupo, foram transformados em média e submetidos à análise de variância, seguida pelo teste de Tukey, com significância $P<0,05$.

\section{Resultados}

Após 24 horas da intoxicação, as dosagens séricas de ALT apresentaram-se aumentadas em todos os animais. Quando analisados os valores do tempo zero como referência, em relação aos tempos subseqüentes, observa-se que, no grupo I ocorreu aumento de 40 a 60 vezes os valores iniciais, no grupo II de 5,8 a 52 e no grupo III de 8,6 a 28,52 os valores do tempo zero (Figura 1 ).

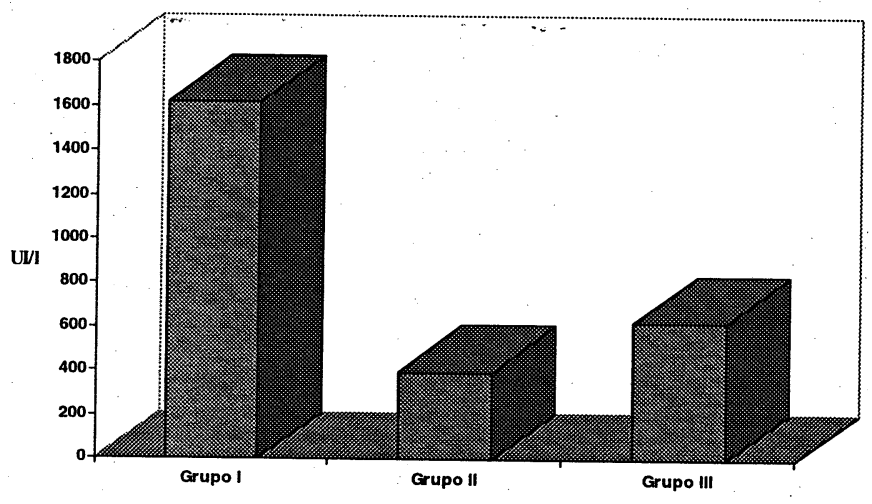

Figura 1: Representação gráfica da variação das médias dos valores da alanina aminotransferase (UI/I), no soro de cães intoxicados pelo tetracloreto de carbono, sem tratamento (Grupo I), tratados com silimarina na dose de $4 \mathrm{mg} / \mathrm{kg}$ (Grupo II) e tratados com silimarina na dose de $8 \mathrm{mg} / \mathrm{kg}$ (Grupo III), obtidos ao final do experimento.

Fontes de aquisição: a Carbono Tetracloreto: Cetus Ind.Com.Prod.Quím. Ltda. Santo Amaro, SP; b Óleo de Milho Gilda: Ind. J. B. Duarte S.A. São Paulo, SP.; ${ }^{\circ}$ Thionembutal: Abbott Laboratórios do Brasil Ltda. São Paulo, SP.; ' Legalon: BYK Química e Farmacêutica Ltda. Diadema, SP.; ${ }^{\circledR}$ Bioclin Test:
Química Básica Ltda. Belo Horizonte, MG 
As dosagens de FA apresentaram-se levemente aumentadas 24 horas após o ínicio do experimento, indicando no grupo I um aumento de 1,3 a 2,6 vezes os valores iniciais, no grupo II até 3,8 vezes e no grupo III 1,25 a 2 vezes os valores prévios à intoxicação. Durante todo o experimento os níveis de FA, na maioria dos animais, apresentaram-se dentro dos limites fisiológicos para a espécie, sendo que ao final do período experimental todos apresentavam valores normais (Figura 2 ).

Todos os animais do grupo I apresentaram soro ictérico 24 horas após a intoxicação, enquanto o mesmo somente ocorreu nos animais 1 e 3 do grupo II e no grupo III somente no animal 4.

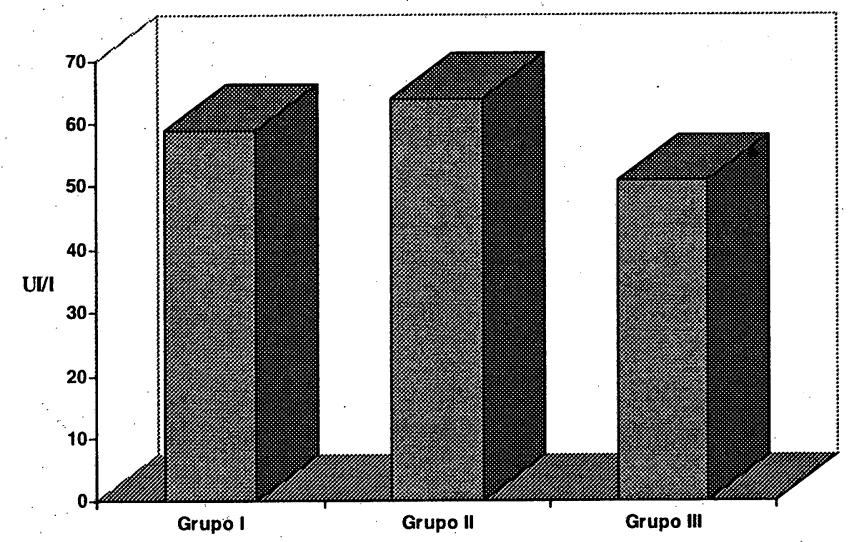

Figura 2: Representação gráfica da variação das médias dos valores da fosfatase alcalina (UI/I), no soro de cães intoxicados pelo tetracloreto de carbono, sem tratamento (Grupo I), tratados com silimarina na dose de $4 \mathrm{mg} / \mathrm{kg}$ (Grupo II) e tratados com silimarina na dose de $8 \mathrm{mg} / \mathrm{kg}$ (Grupo III), obtidos ao final do experimento.

A sintomatologia evidenciada pela totalidade dos animais foi de anorexia no período inicial do experimento e diarréia com estrias de sangue, desaparecendo após 24 horas da intoxicação. Todos os animais apresentaram coloração de mucosas normais, micção diminuída entre 216 e 360 horas do experimento e coloração da urina normal.

Os animais do grupo I apresentaram sensibilidade hepática ao toque chegando a três cruzes. No grupo II, os animais 1, 4 e 5 não apresentaram sensibilidade hepática, o animal 2 apresentou duas cruzes e 0 animal 3 apresentou uma cruz. No grupo III, somente o animal 4 manifestou uma cruz de sensibilidade hepática.

Houve diferença significativa da $A L T,(P<0,05)$, entre os animais tratados e controle, porém não houve diferença significativa entre as doses. O teste de Tukey foi aplicado protegido pelo teste $F$.

Não houve diferença significativa da FA, entre os animais tratados e controle, nem entre doses $(P<0,05)$. $O$ teste de Tukey não foi protegido pelo teste $F$.

\section{Discussão}

Os animais apresentaram sintomatologia semelhante à descrita por Marques et al. (1982), entretanto, não observando-se vômitos e icterícia citados por Perez (1964), Meyer Jones et al. (1983) e Goodman \& Gilman (1991).

A diarréia ocorrida ao início da intoxicação é semelhante à atribuída por Gallagher (1961) à lesão da mucosa gastrointestinal provocada pelo tetracloreto de carbono, que, devido à sua rápida absorção resulta em imediata reversão desta alteração. Segundo Gallagher (1961) e Frimmer (1982), esta absorção ocorre através da veia porta atingindo o fígado como órgão-alvo.

Não há citação na literatura referente à menor sensibilidade hepática, observada neste experimento, nos animais tratados com silimarina, que pode ser atribuída à menor lesão hepática observada através dos níveis séricos de ALT e FA.

Todos os animais apresentaram oligúria, concordando com Goodman \& Gilman (1991), que relataram o envolvimento renal em animais intoxicados pelo tetracloreto de carbono, manifestando-se com oligúria que pode culminar em aproximadamente uma semana com anúria. Tal ocorrência não foi observada nos animais deste experimento.

O aumento das enzimas ALT e FA foi observado em todos os animais, 24 horas após a intoxicação, concordando com Gallagher (1961) que afirma que o aumento da permeabilidade da membrana dos hepatócitos inicia-se entre uma e três horas após a intoxicação pelo tetracloreto de carbono. Ocorre liberação sérica destas enzimas que normalmente são intracelulares, portanto, o aumento nos níveis de ALT e FA ocorre devido ao dano hepático causado pelo agente intoxicante (Conti et al., 1992).

$O$ aumento da ALT foi mais acentuado que a FA, aumentando em até 60 vezes os valores do tempo zero, utilizados como referência, enquanto que a FA aumentou 3,8 vezes, semelhantes aos achados de COLES (1984) que observou aumento de duas a três vezes nos níveis séricos de FA, enquanto que os níveis de ALT cresceram de dez a vinte vezes, em animais intoxicados pelo tetracloreto de carbono.

O maior aumento da ALT do que a FA pode ser atribuído aos danos diretos nos hepatócitos produzidos pelo tetracloreto de carbono, resultando em aumento da permeabilidade da membrana e necrose dos hepatócitos, ocasionando liberação da ALT no plasma, conforme indicação de COLES (1984), Bogin et al. (1989), meyer et al. (1992) e Muriel et al. (1992).

O leve aumento da FA, 24 horas após a intoxicação, não foi significante, concordando-se com Meyer et al. (1992) que afirmam ser uma enzima de indução, necessitando um estímulo para aumentar sua produção; conseqüente- 
mente, seu aumento não é imediato, sendo menor e mais gradual que a ALT. Este aumento, 24 horas após, indica não haver obstrução dos ductos biliares, uma vez que trata-se de uma enzima colestática segundo Cornelius (1989).

O aumento das enzimas hepáticas ocorreu nos três grupos, combinando com trabalhos realizados por Lettéron et al. (1990) e Conti et al. (1992); entretanto, nos animais tratados a ALT foi significantemente menor que nos animais utilizados como controle, concordando com Lettéron et al. (1990) e contrariando Conti et al. (1992) que não obtiveram diferença utilizando doses de $25,82,5$, e $250 \mathrm{mg} /$ $\mathrm{kg}$ de silimarina em ratos intoxicados pelo tetracloreto de carbono.

Em vários experimentos, utilizando-se diferentes agentes causadores de disfunções hepáticas tratados pela silimarina em diferentes dosagens, tais como $100 \mathrm{mg} / \mathrm{kg}$ (WU et al. , 1993) e $200 \mathrm{mg} / \mathrm{kg}$ (Muriel et al., 1992), foram observados menores aumentos dos níveis de ALT e FA nos animais tratados. Os dados obtidos no presente experimento estão parcialmente em conformidade com os autores citados, no qual foi constatado diferença significativa apenas da ALT.

Nos experimentos realizados por Candel et al. (1978) e Muriel et al. (1992), os níveis enzimáticos permaneceram relativamente estáveis, dentro dos limites fisiológicos, contrariando o presente experimento.

Candel et al. (1978), Muriel et al. (1992), Wu et al. (1993) administraram a silimarina anteriormente ao agente causador da disfunção hepática, variando esta administração de 5 minutos (Wu et al., 1993) a 5 dias (Candel et al., 1978), obtendo assim um efeito protetor anterior à hepatopatia. Este fato, associado às altas dosagens de silimarina, pode ser responsabilizado pelo pequeno aumento da ALT e FA em animais tratados.

Neste experimento o tratamento foi iniciado 8 horas após a intoxicação com tetracloreto de carbono, que segundo Gallagher (1961) inicia sua ação imediatamente após sua absorção e, após 6 horas, podem ser detectados sinais de intoxicação através da mensuração das enzimas hepáticas. O tratamento, portanto, foi iniciado após instalada a hepatite tóxica aguda, explicando assim o aumento dos níveis enzimáticos de ALT acima dos limites fisiológicos para a espécie.

Nos experimentos realizados por Salmi \& Sarna (1982) e Buzzeli (1993) foram tratados pacientes humanos portadores de hepatopatia. Salmi \& Sarna (1982) observaram diminuição nos níveis de ALT, mas não de FA em relação ao controle, combinando com o presente trabalho, enquanto que Buzzeli et al. (1993) observaram diminuição da ALT e FA, concordando parcialmente com este experimento.
As alterações das enzimas hepáticas observadas nesta pesquisa indicam um efeito protetor da silimarina no fígado frente à intoxicação pelo tetracloreto de carbono, que segundo Friebrich \& Koch (1979), Valenzuela \& Guerra (1985) e Yao-Cheng (199.1) é atribuído à contenção da peroxidação lipídica pela silimarina, contrariando Lettéron et al. (1990), que afirmam que este efeito somente ocorre quando empregadas altas dosagens de silimarina. Conforme citação de Muriel et al. (1992), esta proteção foi parcial, enquanto que a proteção total ocorreria quando a atividade enzimática é preservada, mantendo-se dentro dos limites fisiológicos para a espécie. Nos animais deste experimento os valores enzimáticos de ALT estiveram acima dos valores normais para a espécie.

Não houve diferença nos níveis de FA entre os três grupos do presente experimento, sendo que um animal de cada grupo apresentou valor de FA além dos limites fisiológicos, que conforme Cornelius (1989) e Meyer et al. (1992) indica a ocorrência de colestase. Nos demais animais, houve pequeno aumento da FA, atribuído por Meyer et al. (1992) à congestão do fluxo biliar causado pela morte dos hepatócitos.

Os três animais que apresentaram colestase já apresentavam níveis elevados de FA antes da intoxicação, provavelmente oriunda de outros tecidos, por não se tratar de uma enzima hepatoespecífica (Kramer, 1984, Bogin et al., 1989, Meyer et al., 1992). Como estes animais aparentavam aproximadamente seis meses de vida, este aumento pode ser atribuído à fosfatase alcalina óssea, proveniente da grande atividade osteoblástica desta fase de crescimento (Cornelius, 1989).

Os animais deste experimento não apresentaram icterícia, porém foi observado soro ictérico em oito animais que, segundo Meyer et al. (1992), é manifestado quando a bilirrubina alcança níveis entre 2 e $3 \mathrm{mg} / \mathrm{dl}$ que, provavelmente, não foi atingida na totalidade dos animais utilizados.

\section{Conclusões}

Diante das observações obtidas no presente experimento é permitido concluir que:

- a intoxicação por tetracloreto de carbono em cães induz o aparecimento de anorexia e diarréia sanguinolenta;

- não ocorreu aumento significativo da FA;

- a utilização da silimarina foi capaz de produzir diminuição nos níveis séricos de ALT, nos animais intoxicados pelo tetracloreto de carbono;

- doses de $4 \mathrm{mg} / \mathrm{kg}$ e $8 \mathrm{mg} / \mathrm{kg}$, a cada 24 horas, por via oral, de silimarina, não determinam diferença significativa, entre elas, da atividade da ALT de cães intoxicados pelo tetracloreto de carbono. 


\section{Abstract}

Acute toxic hepatitis was induced with oral administration of carbon tetrachloride $(0,5 \mathrm{ml} / \mathrm{kg})$. Three groups of five dogs each were used, all animals were intoxicated. Group I served as control while groups II and III received orally $4 \mathrm{mg} /$ $\mathrm{kg} /$ day and $8 \mathrm{mg} / \mathrm{kg} /$ day, respectivelly, of silymarin, for 15 days. Serum ALP and SAP activity levels were measured 24 hours prior to intoxication, then every 48 hour for 15 days. During the first day all animals presented prostration and diarrhea with bloody strains. Signs of pain in response to external palpation was reduced in groups II and III. ALP and SAP were increased in all animals. This increase reached 307.5 and 8.5 fold for ALP and SAP respectivelly. ALP levels were lower in treated animals. In conclusion, the results suggest that silymarin is capable of preventing the elevation of serum ALP levels during carbon tetrachloride intoxication. The apparent liver regeneration effect was not different between the two dosages used.

Keywords: liver; silymarin; dogs.

\section{Referências bibliográficas}

ARCARI, M., BRAMBILLA, A., BRANDT, A. et al. Nuovo complexo di inclusione tra la silibina e la b-ciclodestrina: velocitá di disluzione in vitro e assorbimento in vivo in confronto a formulazione tradicionali. Bollettino Chimico Farmaceutico, v. 131, n. 5, p. 205-209, 1992.

BINDOLI, A; CAVALLINI, L; SILIPRANDI, N. Inibitory action of Silymarin of lipid peroxide formation in rat liver mitochondria and microsomes. Biochemical Pharmacology, v. 26, p. 2405-2409, 1977.

BOGIN, E., OTTO, F., LIPPI, E. et al. Patología clínica veterinaria. Asunción: Instituto Interamericano de Cooperación para la Agricultura, 1989, $192 \mathrm{p}$.

BULLES, H; BULLES,J; KRUMBIEGEL,G et al. Estudios sobre recambio e eliminación de silibina en la rata. Arzneimittel-Forschung, v. 25, n. 6, p. 902-905, 1975.

BUZZELLI,G; MOSCARELLA,S; GIUSTI, A. et al. A pilot study on the liver protective effect of silybin-phosphatidilcholine complex (IdB1016) in chronic active hepatitis. International Journal of Clinical Pharmacology, Therapy and Toxicology, v. 31, n. 9, p. 456-460, 1993.

CANDEL, V.A; GOMEZ, M.L; BAIXAULI, R.P. et al. Estudio experimental de la lesión hepática (hepatitis reactiva inespecífica) en procesos supurativos y necróticos renales. efecto hepatoprotetor de la Silimarina. M.M.W., n. 10, p. 473-491, 1978.

COLES, E.H. Patologia clínica veterinária. 3. ed. São Paulo: Manole, 1984. $566 \mathrm{p}$.

CONTI, M; MALANDRINO, S; MAGISTRETTI, M.J. Protective activity of silipide on liver damage in rodents. The Japanese Journal of Pharmacology, v. 60, n. 4, p. 315-321, 1992.

CORNELIUS, C.E. Liver function. In: KANEKO, J.J. Clinical biochemistry of domestic animal. 4. ed. San Diego: Academic Press, 1989. cap. 14, p. 364-393.

FIEBRICH, F., KOCH, H. Silymarin, an inhibitor of lipoxigenase. Experientia, v. 35, p. 1480-1550, 1979.

FRIMMER, M. Farmacologia e toxicologia em veterinária. 2. ed. Rio de Janeiro: Guanabara Koogan, 1982, 251 p.

GALLAGHER, C.H. The pathology and profiylaxis of poisoning by carbon tetracloride. The Australian Veterinary Journal, p. $131-134,1961$.
GOODMAN, L.S. , GILMAN, A. As bases farmacológicas da * terapêutica. 5. ed. Rio de Janeiro: Guanabara koogan, 1991, $770 \mathrm{p}$.

HAKOVÁ, H.; MISUROVÁ, E.The effect of silymarin and gama radiation on nucleic acids in rats. Journal of Phamacy and Phamacology, v. 45, n. 10, p. 910-912, 1993.

KRAMER, J.W. Clinical enzimology. In: KANECO, J.J. Clinical biochemistry of domestic animal. 4. ed. San Diego: Academic Press, 1989. Cap. 13, p. 338-363.

LA LASTRA, C.A.D; MARTIN, M. J; MARHUENDA, E. Gastric anti-ulcer activity of silymarin, a lipoxygenase inhibitors; in rats. Journal of Pharmacy and Pharmacology, v. 45, n. 11, p. 929-931, 1992.

LETTÉRON, P., LABBE, G., DEGOTT, C. et al. Mechanișm for the protective effects of silymarin against carbon tetrachloride-induced lipid peroxidation and hepatotoxicity in mice. Biochemical Pharmacology, v. 39, n. 12, p. $2027-$ 2034, 1990.

LORENZ,D.; LÜCKER, P.W; MENNICKE,W.H. et al. Pharmacokinetic studies with silymarin in human serum and bile. Methods and Findings in Experimental and Clinical Pharmacology, v. 6, n. 10, p. 655-661, 1984.

MAGLIULO, E; SCEVOLA, D; CAROSI, G.P. Investigations on the actions of silybin of regenerating rat liver. ArzneimittelForschung, v. 29, n. 7, p. 1024-1028, 1979.

MARQUES, D.C; COUTO, E.S; PESSOA, J.M. et al. O emprego da metionina na hepatite tóxica aguda provocada experimentalmente pelo tetracloreto de carbono em cães. Arquivo da Escola de Veterinária da UFMG, Belo Horizonte, v. 34, n. 2, p. 237-239, 1982.

MEYER, D.J., COLES, E.H. RICH, L.J. Veterinary laboratory medicine: Interpretation and diagnosis. Philadelphia: W.B. Saunders, 1992. $350 \mathrm{p}$.

MEYER JONES, L., BOOTH, N.H., McDONALD, L.E. Farmacologia e terapêutica em veterinária. 4. ed. Rio de Janeiro: Guanabara Koogan, 1983. 1000 p.

MURIEL, P.; GARCIAPIÑA, T.; ALVAREZ, V.P. et al. Silymarin protects against paracetamol-induced lipid peroxidation and liver damage.Journal of Applied Toxicology, v. 12, n. 6, p. 439-442, 1992.

PÉREZ,V. Enfermedades del hígado. Buenos Aires: El Ateneo, 1964. $701 \mathrm{p}$. 
SALMI, H.A.; SARNA, S. Effect of silymarin on chemical, functional and morphological alterations of the liver. Scandinavian Journal of Gastroenterology, v. 17, p. 517-521, 1982.

VALENZUELA, A., GUERRA, R. Protective effect of the flavonoid silybin dihemisuccinate on the toxicity of phenyllhydrazine on rat liver. Febs Letters, v.181, n. 2, p. 291-294, 1985.
WU, C.G.; CHAMULEAU, R.A.F.M; BOSCH, K. S. et al. Protective effect of silymarin on rat liver injury induced by ischemia. Virchous Archiv, v. 64, n. 5, p. 259-263, 1993.

YAO-CHENG, R. Advances in pharmacological studies of silymarin. Memórias do Instituto Oswaldo Cruz, Rio de Janeiro, v. 86, n. 2, p. 78-85, 1991.

\section{Prêmio Pesquisa Waltham}

O Prêmio de Pesquisa Waltham é uma realização da ÉFFEM BRASIL, Inc., e vem-se tornando, nos últimos sete anos, um grande estímulo ao desenvolvimento e divulgação de novas informações, pesquisas e avanços da medicina veterinária de animais de estimação. A cada nova edição cresce a participação de estudantes e faculdades de veterinária de todo o Brasil. Destinado aos alunos de Medicina Veterinária dos dois últimos anos de qualquer faculdade de Veterinária do Brasil.

A comissão julgadora é composta de dois veterinários da Éffem Brasil, Inc. e por outros três médicos-veterinários especialmente convidados.

Os vencedores (aluno e orientador) participam do WALTHAM VETERINARY STUDENTS WEEK, na Inglaterra.

Durante essa semana, também estão programadas visitas ao CENTRO DE PESQUISAS WALTHAM e à fábrica da PEDIGREE PETFOODS, unidades do grupo MARS.

Em 1998, com o tema: NUTRIÇÃO E/OU CLÍNICA E/OU CIRURGIA DE CÃES E/OU GATOS, foram inscritos 21 trabalhos, e os vencedores foram:

1" lugar: Trabalho: QUILOTÓRAX EM GATOS

Autora: Renata de Castro M. de Barros

Orientadora: Heloísa Justen Moreira de Souza

Faculdade: Plínio Leite - RJ

$2^{\circ}$ lugar: Trabalho: DERMATOSES RESPONSIVAS AOZINCO EM CÃES

Autora: Maria Cristina Silva Vianna de Souza

Orientadora: Regina Ramadinha

Faculdade: Universidade Federal Rural do Rio de Janeiro - RJ

3ํ lugar: Trabalho: ENDOCARDITE BACTERIANA EM CÃES ASSOCIADA À DOENÇA PERIODONTAL

Autora: Fabiana Buassaly

Orientadora: Patrícia Chamas

Faculdade: UNIP - SP 